\title{
SALIVARY ALPHA-AMYLASE AS A MEASURE OF ANXIETY BEFORE AND AFTER DENTAL TREATMENT FOR VISUALLY AND HEARING-IMPAIRED CHILDREN AND THEIR MOTHERS
}

\author{
EKA S SHOFIYAH ${ }^{1}$, MARGARETHA SOVARIA ${ }^{1}$, MOCHAMAD F RIZAL ${ }^{2 *}$, SARWORINI B BUDIARDJO ${ }^{2}$
}

${ }^{1}$ Department of Pediatric Dentistry Residency Program, Faculty of Dentistry, Universitas Indonesia, Jakarta, Indonesia. ${ }^{2}$ Department of Pediatric Dentistry, Faculty of Dentistry, Universitas Indonesia, Jakarta, Indonesia. Email: Levipedo@gmail.com

Received: 16 September 2017, Revised and Accepted: 3 October 2017

\section{ABSTRACT}

Objective: Visual and hearing impairments are known to profoundly affect children's psychological development, including their anxiety. However, strong emotional relationship with their mother found in these children may help them cope. Measuring salivary alpha-amylase (sAA) in saliva samples is widely used in clinical settings as a reliable, non-invasive biomarker of anxiety level.

Methods: Our objective was to evaluate sAA levels in visually and hearing-impaired children and their mothers before and after dental treatment. This study included 60 children with visual and hearing impairments and their mothers. sAA level of both children and mothers was sampled while they were together in the waiting room before treatment. The children then underwent dental prophylaxis in a separate room, and their post-treatment sAA was measured immediately afterward. At that time, their mother's post-treatment sAA was sampled in the waiting room. Data were analyzed using a Wilcoxon test.

Results: sAA levels were found to differ significantly between pre- and post-dental treatment $(\mathrm{p}<0.05)$.

Conclusions: This difference indicates that reducing maternal anxiety would be of great benefit in reducing anxiety in visually and hearing-impaired children. Practical implications: Appropriately managing anxiety in this group of children can be of great benefit to dentists in daily practice, helping them provide the care that these children need.

Keywords: Salivary alpha-amylase, Anxiety, Children, Sensory impairment, Dental treatment.

(C) 2017 The Authors. Published by Innovare Academic Sciences Pvt Ltd. This is an open access article under the CC BY license (http://creativecommons. org/licenses/by/4. 0/) DOI: http://dx.doi.org/10.22159/ijap.2017.v9s2.32

\section{INTRODUCTION}

Visual and hearing impairments are those conditions of the eyes and ears that are classified as disabilities and health problems that affect communication and performance of daily activities [1]. When such impairments appear during childhood, behavioral development may be disrupted [2]. The assistance of parents, particularly of mothers as primary caregivers, is needed until the child is able to perform daily activities independently [3].This dependency of impaired children on their mothers heightens emotional connection and strengthens the bond between them. For instance, if a mother is anxious about something, her child may feel the same way about it [1].

Anxiety toward dental care is a very common problem that is heightened in people with impaired sensory organs. The incomplete information gathered by impaired senses can induce feelings of fear or anxiety, which in dental treatment may lead to unsuccessful visits. Maciel reported a high prevalence of oral problems in patients with sensory impairments due to difficulties in maintaining oral hygiene without the help of others [4].

Level of anxiety can be measured using self-report analysis, behavioral measures, or by means of biomarker samples in blood, urine, or saliva. Measuring biomarker levels in saliva is a convenient method to use in young subjects, especially in special needs populations because it is a non-invasive technique [5]. Secretion of salivary alpha-amylase (sAA) is triggered by sympatho-adrenomedullary system, and increased sAA is thought to be related to anxiety and discomfort [6].

Anxiety in children with visual and hearing impairments and its relationship to their mothers' anxiety during dental treatment are subjects worthy of further investigation to benefit the quality of dental care, thereby reducing the potential for risk. This study aimed to evaluate the SAA levels in visually and hearing-impaired children and their mothers before and after dental treatment.

\section{METHODS}

This study was clinical experimental research using 60 mother-child pairs, in which the child was age 5, visually and hearing-impaired, and registered at a School of the Sensory Impaired in Jakarta, Indonesia. Children who participated in this study had no previous dental treatment. Mothers and children who had asthma, diabetes, kidney failure, congenital heart disease, salivary gland disorders, and pancreatitis were excluded from our study. This study also excluded mothers and children who were taking beta-blockers, antidepressants, parasympathetic medications, or long-term steroids. Children who did not cooperate during sample taking or who had examinations or sports activities at school on the day of sampling were also excluded from this study.

Before dental treatment, mothers and children waited together in the waiting room, where the first sAA measurements were taken. Then, children were moved to treatment room without their mothers to have their first dental prophylaxis and their second sAA measurement immediately afterward. At the same time, as the second sAA measurement in her child, each mother also had her second sAA measurement in the waiting room. The rooms were separated, so mothers could hear treatment activities but could not see them. sAA measurements were performed using a handheld sAA monitor (Nipro; Osaka, Japan) following manufacturer's instructions. Data were analyzed using Wilcoxon and Spearman's analysis with IBM SPSS Statistics software version 23 . 


\section{RESULTS}

As Table 1 summarizes, the results of measurements showed statistically significant sAA level changes in children with visual and hearing impairments both before and after their first dental treatment. Before treatment mothers and children had undergone the first sAA measurements together in the same room. In contrast, after treatment, mothers' measurements were conducted in the waiting room, and children's were conducted in the treatment room. The children's average sAA level tended to be higher before treatment than after treatment.

A similar trend was found for mothers, as Table 2 summarizes. sAA levels measured before and after their children's treatment differed significantly, with the average level before treatment being higher than after treatment.

Table 3 summarizes a strong positive correlation between sAA level changes in mothers and their children both before and after dental treatment.

\section{DISCUSSION}

sAA has been widely used as a non-invasive biomarker of stress response for more than a decade [7]. Present study found a significant difference in sAA levels of children with sensory impairment before dental treatment, when they were accompanied by their mothers, to after treatment, when they had undergone their first dental treatment without the assistance of their mothers (Table 1). This showed that despite being dependent on their caregiver's help for most daily activities, children with sensory impairments could be independent, even when facing a new challenge, such as their first dental visit. To facilitate this potential independence, assistance and education must be consistently provided with the help of caregivers and everyone else in children's surroundings.

The same results were noted for mothers (Table 2), whose sAA levels were found to be significantly higher before their child's dental treatment than afterward. These data indicate that mothers of sensoryimpaired children actively care about their children's well-being, in particular, regarding their first dental visits. These data are also relevant to Wright's Pediatric Treatment Triangle, which shows the importance of caregivers' involvement in treating pediatric patients [8].

A broad range in sAA levels among samples, regardless of age and gender, is known to be caused by large interindividual variations in the basal level of sAA. Therefore, whereas single sAA measurements do not correlate with norepinephrine levels, two measurements are able to show a significant association when stress responses are correlated [9]. Regardless of this, in general, in our study, sAA scores in both mothers and children were higher before dental treatment, when mothers and children were together in the waiting room. Higher children's sAA scores in the waiting room might be caused by the anticipation on the part of the mothers, whose sensory-impaired children were about to face a new experience that she knew could be quite challenging even for children with normal sensory perception.

As explained by the theory of attachment, mother is the primary figure of attachment after the child's birth and interacts continuously with the child, who slowly forms a structure of knowledge based on interactions between them [10]. This structure of knowledge, which may appear as a strong connection between mother and child, transmits mother's feelings of discomfort to the child. This theory may explain the present study's findings of strong positive correlations between sAA levels in mothers and their children both before and after dental treatment (Table 3).

Being naturally sympathetic to their children, mothers spontaneously prepare them to face their first dental treatment either by verbal or non-verbal cues, which explains why sAA level in both subjects after
Table 1: Sensory-impaired children's sAA levels before and after dental treatment

\begin{tabular}{lll}
\hline $\begin{array}{l}\text { sAA level in sensory-impaired } \\
\text { children }\end{array}$ & $\begin{array}{l}\text { Average } \\
\text { (minimum-maximum) }\end{array}$ & $\mathbf{p}^{*}$ \\
\hline $\begin{array}{l}\text { Before dental treatment } \\
\text { After dental treatment }\end{array}$ & $\begin{array}{l}29.5(2-113) \\
18(1-73)\end{array}$ & 0.00 \\
\hline *Wilcoxon signed-rank test, $\mathrm{p}<0.05$, sAA: Salivary alpha-amylase &
\end{tabular}

*Wilcoxon signed-rank test, $\mathrm{p}<0.05$, sAA: Salivary alpha-amylase

Table 2: Mother's sAA levels before and after children's dental treatment

\begin{tabular}{llc}
\hline Mothers' sAA levels & $\begin{array}{l}\text { Average } \\
\text { (minimum-maximum) }\end{array}$ & $\mathbf{p}^{*}$ \\
\hline Before children's dental treatment & $43(2-163)$ & 0.00 \\
After children's dental treatment & $27.5(1-155)$ & \\
\hline *Wilcoxon signed-rank test, p<0.05, sAA: Salivary alpha-amylase &
\end{tabular}

Table 3: Correlation coefficients of difference in sAA levels in mothers and sensory-impaired children before and after dental treatment

\begin{tabular}{ll}
\hline & $\begin{array}{l}\text { Difference in sAA level in } \\
\text { sensory-impaired children } \\
\text { before and after dental } \\
\text { treatment }\end{array}$ \\
\hline $\begin{array}{ll}\text { Difference in sAA level in mothers } \\
\text { before and after children's dental }\end{array}$ & $\mathrm{r}=0.798$ \\
treatment & $\mathrm{n}=60.00^{*}$ \\
\hline
\end{tabular}

*Spearman's correlation test, $\mathrm{p}<0.05$, sAA: Salivary alpha-amylase

dental treatment is lower. As the children had been securely attached to their mothers since birth, they realized more self-reliance and selfesteem, thus boosting their confidence to face new challenges [11].

While conducting dental prophylaxis, our operator applied noninvasive, non-pharmacologic behavior management approaches, mostly by modifying tell-show-do approach according to each child's sensory condition. Tell-show-do method permits children to learn a stimulus-response association by introducing each component step-bystep, therefore, avoiding the fear of the unknown [8].

In response to this approach, most children with sensory impairments found themselves able to cope with the treatment. Therefore, their sAA levels decreased, despite the fact that they were deprived of the company of their mothers, who waited in a separate room during the dental prophylaxis process. In our study, mothers could still hear what was going on in the treatment room. Because they did not hear any disquieting sounds from their children, the mothers felt relieved, and their sAA levels after the treatment were recorded as being lower than before the treatment. Although some subjects were found to have increased sAA levels after dental treatment, this study found a strong positive correlation between mothers and their children (Table 3)

The present study's finding of higher sAA levels before than after dental treatment indicates that reducing maternal anxiety could greatly help to reduce anxiety in children with visual and hearing impairments.

\section{CONCLUSIONS}

The anxiety of children with visual and hearing impairments and their mothers was found to be significantly higher before dental treatment than after. These results showed that strong connection between mother and child could affect child's behavior when facing dental visits. 
Research on a wider range of special needs children during dental care is recommended; as all special needs children have a high rate of oral problems. Appropriately managing anxiety in this group of children can be of great benefit to dentists in daily practice to help them provide the care that these children need.

\section{ACKNOWLEDGMENT}

This research was carried out under grants from Hibah Publikasi Internasional Terindeks Untuk Tugas Akhir Mahasiswa (PITTA) 2016, Directorate of Research and Community Engagement, Universitas Indonesia and University of Indonesia Oral Sc. Research Center (UIOSRC). The publication of this manuscript is supported by Universitas Indonesia.

\section{REFERENCES}

1. du Feu M, Fergusson K. Sensory impairment and mental health. Adv Psychiatr Treat 2003;9:95-103.

2. Sunanto J. Anak dengan Gangguan Penglihatan. ???: Universitas Pendidikan Indonesia; 2014.

3. Hindley P, Salt A. The hearing or visually impaired child models of deafness. In: Martin A, Volkmar FR, editors. Lewi's Child and Adolescent Psychiatry: AComprehensive Textbook. $4^{\text {th }}$ ed. Philadelphia, PA: Lippincott Williams \& Wilkins; 2007. p. 67-76.

4. Maciel MA, Cordeiro PM, D'Avila S, Godoy GP, Alves RD, Lins RD. Assessing the oral condition of visually impaired individuals attending the Paraíba Institute of the Blind. Rev Odonto Cienc 2009;24:354-60.

5. Noorani H, Joshi HV, Shivaprakash P. Salivary alpha amylase as a noninvasive biomarker for dental fear and its correlation with behavior of children during dental treatment. Int J Clin Pediatr Dent 2014;7:19-23

6. Adina N. Pengaruh Positive Images "Berkunjung ke Dokter Gigi" terhadap Kecemasan Anak (Kajian terhadap Salivari Alpha-amylase). : Universitas Indonesia; 2015.

7. Kang Y. Psychological stress-induced changes in salivary alphaamylase and adrenergic activity. Nurs Health Sci 2010;12:477-84.

8. Wright GZ, Kupietzky A. Behaviour Management in Dentistry for Children. $2^{\text {nd }}$ ed. Iowa: John Wiley \& Sons, Inc.; 2014. p. 248.

9. Nater UM, Rohleder N. Salivary alpha-amylase as a non-invasive biomarker for the sympathetic nervous system: Current state of research. Psychoneuroendocrinology 2009;34:486-96.

10. Bowlby J. Attachment and Loss. New York: Basic; 1982.

11. Sroufe LA. Early relationships and the development of children. Infant Ment Health J 2000;21:67-74. 